\title{
An Integrated Stroke Model with a Consistent Penumbra for the Assessment of Neuroprotective Interventions
}

\author{
Dong Yang ${ }^{a, b}, f$ Yukako Nakajo ${ }^{a, e}$ Koji lihara $^{b}$ Hiroharu Kataoka $^{b}$ \\ Jyoji Nakagawara $^{\mathrm{b}, \mathrm{c}}$ Qiang Zhao ${ }^{\mathrm{a}, \mathrm{g}}$ Hiroji Yanamoto ${ }^{\mathrm{a}, \mathrm{d}}$ \\ a Laboratory of Neurology and Neurosurgery, National Cerebral and Cardiovascular Research Center, bepartment of \\ Neurosurgery and 'Integrated Stroke Imaging Center, National Cerebral and Cardiovascular Center, Suita, Japan, and \\ ${ }^{d}$ Division of Surgical Medicine, Department of Cardiovascular Science, Osaka University Graduate School of Medicine, \\ Suita, Japan; ${ }^{e}$ Research Laboratory, Rakuwa-kai Otowa Hospital, Kyoto, Japan; ${ }^{f}$ Department of Neurosurgery, China- \\ Japan Friendship Hospital, Beijing, and ${ }^{9}$ Department of Neurosurgery, Baoding No. 1 Hospital, Baoding, PR China
}

\section{Key Words}

Animal model · Ischemic stroke · 3-vessel occlusion .

Surgical procedures . Preclinical study

\begin{abstract}
Background/Aim: A longer period of vessel occlusion reduces the coefficient of variation of the infarct lesion size ['infarct variation coefficient' (IVC)] due to a gradual expansion of the lesion within a limited territory defined by the vascular anatomy, but it increases the mortality rate. A crucial issue in the induction of experimental focal cerebral ischemia has been to achieve a low IVC value and a low mortality rate. We attempted to improve IVC and mortality using the 3-vessel occlusion model. Methods: We introduced a new, transtemporal fascia approach to expose the zygomatic arch, in which the fascia of the temporal muscle is cut and retracted dorsally together with the facial nerve and the vein en bloc. Results/Conclusion: The approach avoided traumatic venous bleeding around the zygomatic arch. We established a bloodless model of focal ischemia that can produce a consistent degree of reduction in the regional cerebral blood flow within the ischemic penumbra. The model, charac-
\end{abstract}

\begin{tabular}{ll}
\hline KARGER & $\begin{array}{l}\text { ( } 2013 \text { S. Karger AG, Basel } \\
0014-3022 / 13 / 0712-0004 \$ 38.00 / 0 \quad \text { Karger }\end{array}$ \\
E-Mail karger@karger.com & $\begin{array}{l}\text { This is an Open Access article licensed under the terms of the } \\
\text { www.karger.com/ene }\end{array}$ \\
& $\begin{array}{l}\text { Creative Commons Attribution-NonCommercial 3.0 Un- } \\
\text { ported license (CC BY-NC) (www.karger.com/OA-license), } \\
\text { applicable to the online version of the article only. Distribu- } \\
\text { tion permitted for non-commercial purposes only. }\end{array}$
\end{tabular}

terized by a 15 -min ischemia, an IVC of $15-21 \%$, and low mortality after ischemia, is expected to produce reliable preclinical evidence in the assessment of neuroprotective interventions for ischemic stroke. The entire procedure is presented in the online supplementary video (www. karger.com/doi/10.1159/000356048). @ @ 2013 S. Karger AG, Basel

\section{Introduction}

Current knowledge on the pathophysiology of ischemic stroke is largely based on research utilizing animal models of transient, focal cerebral ischemia that mimic ischemic stroke induced by the occlusion of the middle cerebral artery (MCA) with rich collateral anastomosis, mostly combined with simultaneous, tandem, or multiple occlusion of cerebral arteries [1]. Focal ischemia models have played an important role in understanding the pathophysiology of cerebral infarction, but existing mod-

Dong Yang and Yukako Nakajo contributed equally to this study.

H. Yanamoto, MD, DMSc

Laboratory of Neurology and Neurosurgery

National Cerebral and Cardiovascular Research Center

5-7-1 Fujishiro-dai, Suita, Osaka 565-8565 (Japan)

E-Mail hyanamot@ res.ncvc.go.jp 
els have limited reliability for evaluating neuroprotective interventions as many favorable results obtained in animal models have not been translated into human clinical studies [2-6].

Focal cerebral ischemia, excluding the lacunar type, occurs due to simultaneous multiple vessel occlusion, with or without preexisting occlusion or stenosis, causing a significant reduction of regional blood flow ( $\mathrm{rCBF}$ ) below a critical level. Developmentally rich collateral anastomoses exist throughout the brain, including the neocortex; this is the cerebrovascular reserve system, a potent mechanism for the rescue of brain tissue from critical reductions of $\mathrm{rCBF}$, comprising multiple feeding arteries that increase blood supply to ischemic territories. Electrophysiological dysfunction is regarded as a key event in the pathogenesis of ischemic brain injury. A reduction in rCBF below $15-18 \mathrm{ml} / 100 \mathrm{~g} / \mathrm{min}$ was found to cause immediate electrical dysfunction of neurons (expressed as electrical silence), as observed by flattening of the EEG or abolition of somatosensory-evoked potentials in cats, baboons, and humans [7-9]. That portion of the brain below the threshold for complete electrical silence on EEG (reversible depolarization), but above the threshold for complete energy failure (persistent or terminal depolarization), is referred to as the ischemic penumbra [7-9]. Persistent or terminal depolarization in the ischemic core triggers repeated ripple-like spreading depolarization that spreads to the surrounding structures, referred to as peri-infarct depolarization, which causes transient reductions in $\mathrm{rCBF}$ and transient or persistent depression of electrical activity (electrical silence on EEG) [10-14]. Importantly, the peri-infarct depolarization phenomenon propagates not only in the penumbra, but also to the healthy surrounding structures, causing transient electrical silence on EEG accompanied by arterial constriction or dilatation [13].

The state in which there is reduced $\mathrm{rCBF}$ but where a normal cerebral metabolic rate of oxygen is maintained by increased the oxygen extraction fraction with compensatory dilatation of collateral arteries is referred to as misery perfusion, or stage 2 [15]. Although energy metabolism is preserved both in the area of misery perfusion and the ischemic penumbra, extended tissue viability is maintained only in the area of misery perfusion, at least for more than a few hours without any intervention $[16,17]$. In a review article, Hossmann [16] redefined the concept of the ischemic penumbra as a region of constrained blood supply with preserved energy metabolism, and noted that the region would be infarcted within a few hours by the peri-infarct depolarization phenomenon. It has

Reproducible Ischemic Penumbra in the Mouse Brain been postulated that the recurrent peri-infarct depolarization observed on measurement of the direct current potential, with subsequent reduction in the $\mathrm{rCBF}$, is the principal cause of gradual tissue damage in the penumbra [13].

In humans, an $\mathrm{rCBF} \geq 19 \mathrm{ml} / 100 \mathrm{~g} / \mathrm{min}$, or $\geq 32 \%$ of preischemic control values, maintains normal cerebral function [18]. Irrespective of species differences, a reduction below $15-19 \mathrm{ml} / 100 \mathrm{~g} / \mathrm{min}$, or $<25-32 \%$ rCBF of preischemic control values, generates functional impairment (i.e. electrical silence on EEG) [7, 11, 19]. More severe ischemia, below the lower threshold of $6 \mathrm{ml} / 100 \mathrm{~g} / \mathrm{min}$ $\mathrm{rCBF}$, or $<10 \% \mathrm{rCBF}$ of preischemic control values, causes immediate persistent depolarization, complete energy failure, and cell death $[7,11,18,19]$. In spontaneously hypertensive rats, however, persistent ischemic depolarization was observed in a region where it was $<50 \mathrm{ml} /$ $100 \mathrm{~g} / \mathrm{min}$, or $38 \pm 13 \mathrm{ml} / 100 \mathrm{~g} / \mathrm{min}$ on average [20], and cerebral infarction developed in a region where there was $<50 \mathrm{ml} / 100 \mathrm{~g} / \mathrm{min} \mathrm{rCBF}[21]$. Thus, the threshold for the induction of cerebral infarction is not always the same, but it is affected by individual vascular pathophysiology such as chronic hypertension.

In a study of positron emission tomography performed several hours after the onset of ischemic stroke, tissue with an $\mathrm{rCBF}<12 \mathrm{ml} / 100 \mathrm{~g} / \mathrm{min}$, or $<20 \% \mathrm{rCBF}$ of preischemic control values, became infarcted on later computed tomography [9]. However, when thrombolytic reperfusion therapy was successful in the acute phase, it was possible to salvage $77.3 \%$ of the gray matter at risk, in which the initial rCBF (measured within $3 \mathrm{~h}$ after the ictus, before a therapeutic intervention) was $<12 \mathrm{ml} / 100 \mathrm{~g} /$ min, or $<20 \%$ [9]. Taken together, an $\mathrm{rCBF}<20 \%$ was found to cause irreversible tissue damage in a short period of time (within a few hours), but was not the threshold that caused terminal depolarization, leading to immediate cell death.

Any animal model that is used to evaluate the degree of cerebral damage due to focal ischemia must induce a critical but treatable area - the ischemic penumbra - between the upper and lower thresholds of 10 and $32 \%$ of the $\mathrm{rCBF}$ at least for a certain period, and any neuroprotective intervention must be initiated within the limits of viability of neurons in this area $[7,11,18]$. Because the basal ganglia are not protected by a system of vascular reserve, severe ischemia, $\mathrm{rCBF}<10 \%$, occurs after obstruction of the MCA involving the lenticulostriate arteries [19]. Belayev et al. [22], by analyzing topographic hemodynamics in the ischemic region induced by the method of intraluminal thread insertion (ITI) in rats in which the 
coefficient of variation of the size of the infarct ['infarct variation coefficient' (IVC), i.e. percent of standard deviation $(\mathrm{SD})$ of the mean infarct lesion volume] was $8 \%$ ( $\mathrm{n}=5$ /group), defined the region where $\mathrm{rCBF}$ is reduced to $20-40 \%$ of control (contralateral) values as the 'penumbra', and the more ischemic region with $<20 \%$ of control $\mathrm{rCBF}$, which contributed $70 \%$ of the infarcted lesion, as the 'core'. However, glucose metabolism in the penumbra was normal at the end of ITI-induced 2-hour ischemia $[22,23]$, indicating that the degree of reduction in rCBF was not sufficient to induce irreversible tissue damage within $2 \mathrm{~h}$ in rats (i.e. $12 \mathrm{~h}$ in humans, as described in the Discussion). Although the reason is unknown, glucose metabolism in the penumbra, which was normal at the end of ischemia, decreased by $40-60 \% 1 \mathrm{~h}$ after circulation was reestablished (induced by thread removal) [23].

The various models of focal ischemia each have their advantages and disadvantages, with associated error rates at which no infarction or fatal ischemia occur. The ITI method, utilized worldwide [24-28], involves insertion of a nylon thread from the common (CCA) or external carotid artery into the internal carotid artery, with the objective of occluding the orifice of the ipsilateral MCA in a blind manner.

Insertion of the thread causes simultaneous tandem occlusion or stenosis involving the ipsilateral ICA, with or without the ipsilateral anterior cerebral artery, posterior communicating artery, and posterior cerebral artery. While the ITI method does not require a burr hole and intracranial surgery, the level of reduction in $\mathrm{rCBF}$ varies because of slight differences in individual vasculature and the contribution of the coagulation system and normal cerebrovascular reserve system. The size of the ischemic lesion varies widely [29], producing a subgroup of animals with no/faint and huge/fatal infarction. The ITI model is associated with substantial variability in the coefficient of variation of the size of the infarct (IVC), ranging from 5 to $200 \%$ [1]. Due to the expandable IVCs, many studies with low IVCs have used individual (laboratory-specific) animal exclusion criteria that are applied after the insertion of the thread.

A review of the absolute values of lesion sizes obtained by protocols using the ITI method described in the literature revealed a great variability in IVC that ranged from 5 to $102 \%(\mathrm{n}=19)$; a range almost 2 times wider than that of the 3-vessel occlusion (3-VO) method, which has been found to have a range in variability from 13 to $52 \%(\mathrm{n}=$ 19) $[29,30]$. After temporary focal ischemia for $2-3 \mathrm{~h}$, there was a significant difference in the IVCs: $34 \%$ in the
ITI model, versus $22 \%$ in the $3-\mathrm{VO}$ model $(\mathrm{p}=0.026, \mathrm{t}$ test, $\mathrm{n}=19$ in each model) [29]. In addition to the difference in vascular reserve between the basal ganglia and the cortex, abundant neurons in the striatum are highly vulnerable to ischemia $[31,32]$. Such inconsistent vulnerability of neurons in the basal ganglia is also a factor that contributes to an increase in the IVC value.

The mortality rate is not always reported in the ITI model, but has been reported to be $71 \%$ at $24 \mathrm{~h}$ after 2 -hour ischemia in rats [33]. The fact that all animals died within $32 \mathrm{~h}$ after the induction of ischemia in the original ITI report [24] demonstrates that thread insertion into the cerebral artery is not 'less invasive' compared to open surgery. In the case of human intravascular intervention, the use of systemic heparin and a heparin-coated catheter are essential to prevent blood coagulation in and around the catheter, as well as subsequent thrombus/embolism formation.

The insertion of a nonheparinized nylon thread, i.e. a biologically active (foreign) substance sitting in the arterial lumen for a prolonged period ( $\geq 30 \mathrm{~min}$ ), activates the blood coagulation system, resulting in multiple uncontrollable embolisms [34-36]. When the ITI technique was applied to $\mathrm{C} 57 \mathrm{BL} / 6$ mice, the mortality rate was $17-37 \%$ at $24 \mathrm{~h}$ after $60-\mathrm{min}$ ischemia [37], and $25-80 \%$ at $48 \mathrm{~h}$ after 30- to 60-min ischemia [38]. However, information on acute death is often not provided in descriptions of the ITI model [39-41]. We speculate that failure to disclose (or lack of recognition of the importance of disclosing) the number of excluded animals in each group after the insertion of the thread (or the total number of animals in each group at entry) is the primary reason for difficulties related to poor interlab comparability in the ITI model. While it has become increasingly apparent that transparent reporting of individual criteria and prior incorporation of such criteria into the protocol are essential, few papers fulfill these requirements [42].

A model of focal ischemia that removes or minimizes the need for animal exclusion during and after ischemia is expected to preclude observation bias and reporting of false positive results. Among the strategies to induce focal ischemia, the 3-VO method sufficiently suppresses the compensatory effect of the cerebrovascular reserve system. We found that temporary occlusion of both CCAs in conjunction with permanent unilateral occlusion of an MCA consistently produces focal ischemia, $\mathrm{rCBF}$ that is $>10 \%$ but $<20 \%$, and adequate reperfusion in the cortex, achieving good reproducibility for the homogeneous development of cortical infarction [29]. However, removal of the zygomatic arch to open a burr hole carries a risk of venous bleeding that might increase IVC values. 
To improve the quality of preclinical assessment and reproducibility of data, we developed a model of focal ischemia that has a lower IVC value and lower mortality in the acute phase. Here, we demonstrate techniques that involve sharp dissection, including a detailed description of the transtemporal muscle (fascia) approach, with the use of multiple figures and an online supplementary video (for all online supplementary material, see www. karger.com/doi/10.1159/000356048) that facilitates the training of researchers who have not tried or succeeded in implementing the 3-VO model. This bloodless surgery resulted in a brief ischemic time, a short skin-to-skin time, and a low IVC value, with low mortality.

\section{Experimental Procedure}

\section{Materials and Reagents}

For the assessment of the rCBF and the development of cerebral infarction/neurological deficit, C57BL/6J male mice (CLEAJapan, Tokyo, Japan) weighing 23-24 g and being 8 to 9 weeks old were used; for the comparison of the survival rate, the mice were $26-27 \mathrm{~g}$ and 12 to 13 weeks old. The following reagents were used: halothane, $20 \%$ mannitol, heparinized sodium phosphate-buffered saline (PBS, $10 \mathrm{mM}, \mathrm{pH} 7.5$ ), and a $2 \%$ solution of 2,3,5-triphenyltetrazolium chloride (TTC).

\section{Equipment}

Equipment for Monitoring Physical Parameters

- Biological amplifier (AP-611G, AP-600G; Nihon Kohden, Tokyo, Japan)

- Digital thermometer (NS-TC10 temperature controller, Neuroscience, Inc., Tokyo, Japan)

- Blood pressure meter (BP-98AW; Softron Co. Ltd., Tokyo, Japan)

Equipment for Anesthesia

- Halothane vaporizer (Halowik Muraco Medical Co., Ltd., Tokyo, Japan)

- Body warmer (K-module, model: K-20 64-N020; Baxter, Deefield, Ill., USA)

\section{Surgical Instruments}

- Surgical microscope (OME 5000; Olympus, Tokyo, Japan, M 650; Leica, Germany, or Hi-R 700; Mölle-Wedel GmbH, Germany)

- Small animal holder (NC8-1S; Naigai, Tokyo, Japan)

- Bipolar coagulator (AESCULAP tb50; B. Braun Melsungen AG, Melsungen, Germany)

- Micorforceps connected to the coagulator (GK690R, B. Braun Melsungen AG)

- Bone rongeur for zygomatic arch, double-action curved delicate (16020-14, FST, Germany)

- Electric drill for opening the burr hole (Proxxon ${ }^{\circledR}$, No. 28593 drill, No. 28750 engraving cutter; Kiso Power Tools, Osaka, Japan)

Reproducible Ischemic Penumbra in the Mouse Brain
- Microforceps (Inox-3; Dumont, Montignez, Switzerland)

- Microsurgery scissors (AESCULSP FD012R, B. Braun Melsungen $\mathrm{AG}$ )

- Needle and a thread for skin sutures (63B-173 \& Silk 5-0 or 6-0, Matsuda Ika, Tokyo, Japan)

Instruments for Clipping the CCA

- Clips for the CCA occlusion (No. 07-096-01 YZ-200 (25g); Mizuho Ika Kogyo, Tokyo, Japan)

- Clip holder (07-097-00, Mizuho Ika, Tokyo, Japan)

Tools for Cerebral Infarct and $\mathrm{rCBF}$ Analyses

- Animal brain cutter (MBSC-01S, Neuroscience, Inc., Tokyo, Japan)

- Image analyzer (Win $\mathrm{ROOF}^{\circledR} ;$ Mitani, Fukui, Japan)

- Laser-Doppler blood flowmetry (TBF-LN1; Unique Medical, Tokyo, Japan)

- Glass fiber-type laser probe (order made for the mouse brain, Unique Medical)

\section{Animal Care}

This protocol was designed in accordance with the guidelines and regulations issued by the Animal Care and Use Committee of the National Cerebral and Cardiovascular Center in Japan. Every effort is made to minimize the number of animals used and their suffering. All mice are allowed food and water ad libitum before and after the ischemic induction.

Induction of Temporary Focal Ischemia

Preparation for Surgery

- Induce anesthesia by applying a mixture of $1.0-1.5 \%$ halothane in oxygen and nitrogen. Lower the concentration of halothane between 0.2 and $1.0 \%$ during operation. Note: observe the vital signs at all times point during the operation. Adjust the depth of anesthesia (deep or shallow) according to painful or painless procedures and time. Identify and solve emerging issues promptly if body temperature, blood pressure, or heart rate becomes abnormal, so as to ensure smooth and regular spontaneous respiration and uniform anesthesia, as well as minimize differences among individuals and increase comparability.

- Suture the left eyelids to protect the eyeball from craniofacial surgery. Shave hair around the left zygomatic and frontal neck area widely with razor blade with $70 \%$ alcohol. Note: avoid hypothermia during hair shaving by minimizing use of alcohol.

- Monitor the heart rate, systemic and diastolic blood pressure via the proximal tail artery. To avoid the use of a muscle relaxant that suppresses the respiratory function, careful adjustments of halothane concentration are needed by monitoring spontaneous respiration and the physiologic parameters.

- Regulate rectal (core) temperature at the range, $37 \pm 0.5^{\circ} \mathrm{C}$, by means of a heating lamp and the body temperature controller with a heating table and a thermometer before ( $5 \mathrm{~min})$, during $(0,5,10,15 \mathrm{~min})$ and after surgery $(15 \mathrm{~min})$.

Exposure of the CCAs for the preparation of 3-VO.

- In a supine position, make a midline incision at the front neck, lift up the fat tissue and the thyroid gland rostrally, and expose both CCAs (fig. 1: 1-4). 

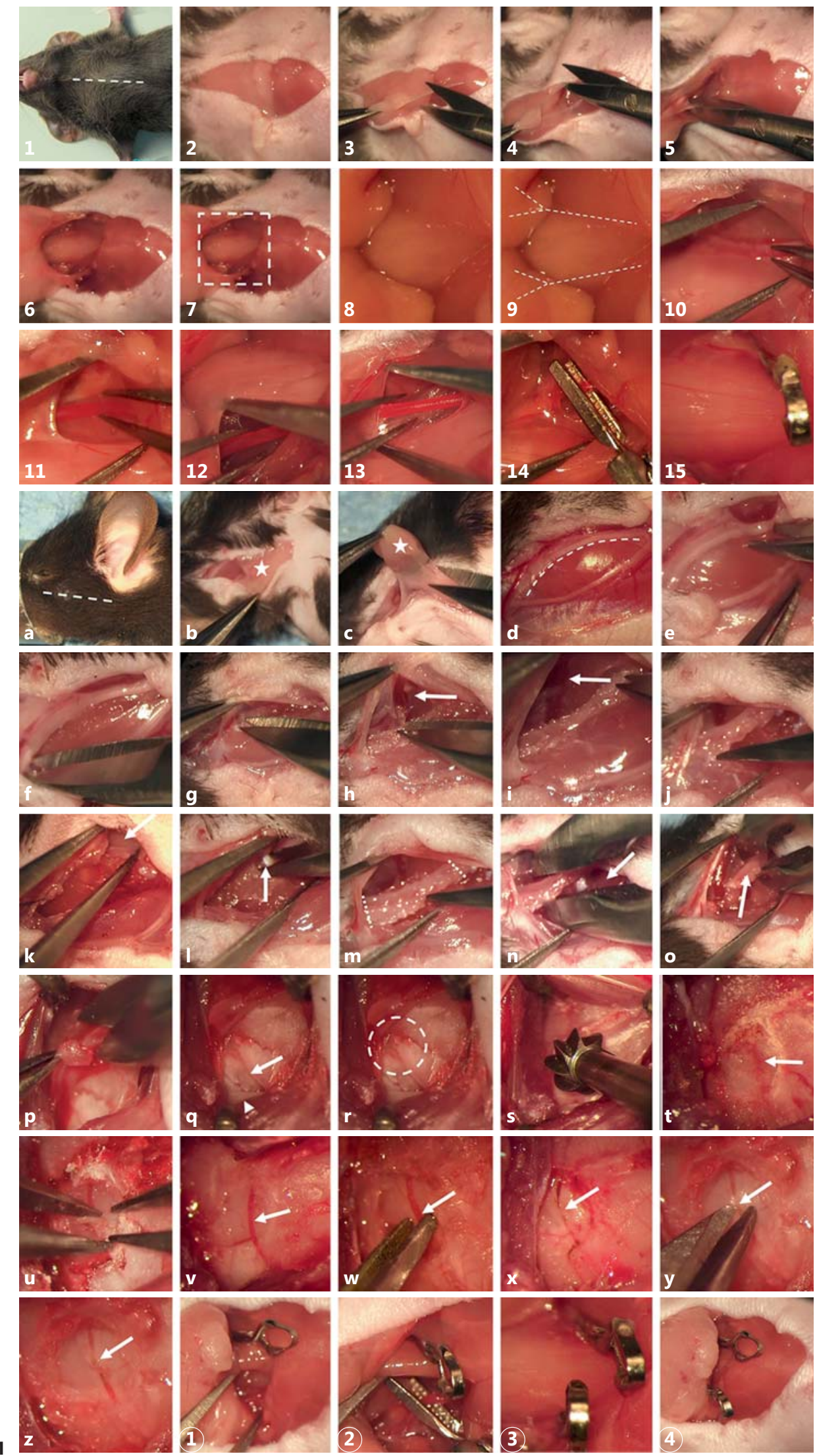
- After the exposure of CCAs (fig. 1:4-13), occlude the left CCA at the location just proximal to the CCA bifurcation using a microclip (fig. 1: 14-15). The temporary occlusion of the left CCA prior to the MCA is beneficial to reduce the volume of the vascular bed during the procedure in the left face. Note: when exposing the CCAs, always dissect and separate the connective tissues, avoiding pinching of the muscles, nerves, veins, and arteries.

\section{Induction of 3-VO}

- Place the head in the right lateral position, keeping the lower body trunk in a supine position, and incise skin horizontally along the left zygomatic arch to expose the fascia of the temporal muscle underneath (fig. 1a-d).

- After exposing the fascia of the left temporal muscle, cut the fascia along the ventral edge of the zygomatico-orbital branch of the facial nerve that is running on the fascia along the zygomatic arch horizontally (fig. 1e, f). Retract the nerve together with the orbitozygomatic vein that runs dorsoparallel to the nerve, cut the muscle under the fascia horizontally, and expose the surfaces of the zygomatic bone (fig. $1 \mathrm{~g}-\mathrm{j}$ ). This transtemporal fascia approach can avoid damage to the orbitozygomatic vein, and occlusion-induced delayed venous bleeding. Open the capsule of the temporomandibular joint (temporomandibular articulation) (fig. 1k). After cutting the sphenomandibular ligament, cut and remove the zygomatic arch with the rongeur (fig. 11-o), paying attention not to damage the external jugular vein running at the right corner in the surgical window. Note: in this step, avoid tear injuries to the veins by the sharp tips of the microforceps.
- Retract the mandible bone ventrally, and expose the left temporal bone (fig. 1p). Note: the view of the temporal bone can be maintained by hand-made rectangular needle retractors. Installation, traction, and removal of the retractors should be performed carefully to prevent vice-associated injury of the muscle or venous tissue.

- Drill a 1-mm diameter burr hole at a point $2 \mathrm{~mm}$ superior and rostral to the foramen ovale, at the location of nerve impression on the temporal bone by the extracranial trigeminal nerve root (fig. 1q-t). Through the drilled burr hole, the left MCA (red) and the lateral edge of the left olfactory tract (white) are seen. Note: drill the skull until the internal plate of the skull cracks, leading to simultaneously tearing of the dura mater and a small amount of cerebrospinal fluid leakage.

- Remove the cracked bone pieces with microsurgical forceps and expose the left MCA (fig. 1u, v). Note: in the removal of the bone pieces, hold the pieces away from the MCA trunk to avoid damage to the MCA.

- Cauterize the MCA using a bipolar coagulator at the lateral edge of the olfactory tract, with the output power around 0.20.3 (fig. $1 \mathrm{w}, \mathrm{x}$ ). After the cauterization, cut the MCA with microscissors permanently (fig. 1y, z). Note: wash the surgical field with $20 \%$ mannitol before electrocoagulation of the MCA to prevent char from forming on the tips of the bipolar forceps [43]. The MCA may stick to the surface of the forceps during the char formation and bleed.

- Immediately after the permanent obstruction of the MCA, clipocclude the right CCA just proximal to the bifurcation, which completes the 3-VO (fig. 1: (1)-(4)). After the induction of focal
Fig. 1. The surgical procedures to induce temporary focal ischemia in the mouse cortex are divided into 3 major steps. 1-15 Surgery at the neck for the occlusion of the left CCA for the preparation of the head surgery. a-z Surgery of the head including the removal of the left zygomatic arch and permanent occlusion of the left MCA. 1-4 Achievement of 3-VO by occluding the right CCA. a Schematic diagram of the incision set on the left head (the dashed line). The left eyelids are closed with a suture. b On the right side, sublingual gland appears under the skin (asterisk). c Remove the gland (asterisk) by cutting the surrounding connective tissues. d Expose the surface of the temporal muscle (fascia) and identify the zygomatico-orbital branch of the facial nerve that runs horizontally on the muscle (the dashed line shows the ventral edge of the nerve branch). e Cut the fascia linearly at the ventral edge of the facial nerve using microscissors. $f$ Free the facial nerve and the facial vein together with the upper edge of the temporal fascia from underneath the temporal muscle and retract 'the nerve, vein and the fascia complex' dorsally using microforceps. $\mathbf{g}$ Expose the surface of the zygomatic arch by cutting and separating the bare muscle band horizontally. $\mathbf{h}$ Retract the orbitozygomatic vein (arrow) dorsally together with the fascia and the nerve, and expose the dorsal edge of the zygomatic arch. i Complete the exposure of the upper edge of the zygomatic arch, completely detaching the orbitozygomatic vein coming behind the arch (arrow). $\mathbf{j}$ Cut off the temporal muscle from the ventral zygoma with scissors and expose the ventral edge of the zygomatic arch. $\mathbf{k}$ Insert the tips of a microforceps and stretch/tear the capsule of the temporomandibular joint to open the mandibular joint (arrow). I Cut the sphenomandibular ligament on the left of the joint (arrow). $\mathbf{m}$ Complete the exposure of the zygomatic arch (dotted lines: the bilateral borders to cut off). n Cut the cephalad side of the zygomatic arch with the rongeur, not damaging the internal jugular vein at the right corner (arrow). o Cut the caudal side of the zygomatic arch (arrow). p Cut off the muscles attached to the temporal bone to prepare for drilling. $\mathbf{q}$ Confirm the extracranial part of the trigeminal nerve (triangle) and find the bony impression of the trigeminal nerve on the temporal bone (arrow). $\mathbf{r}$ The location of the burr hole (dashed circle). $\mathbf{s}$ Mill the temporal bone by the burr. $\mathbf{t}$ After the drilling of the temporal bone, the MCA is visible through the bone window (arrow). $\mathbf{u}$ Remove the pieces of residual thin bone flaps with the microforceps. $\mathbf{v}$ Exposed MCA trunk shown by the arrow. w Collapse using the bipolar coagulation and occlude the left MCA permanently (arrow: the location to coagulate). $\mathbf{x}$ The coagulated MCA (completely intercepted site: arrow). y Cut the MCA at the intercepted site to prevent an incidental recanalization (arrow: the collapsed MCA). $\mathbf{z}$ The edge of the intercepted MCA (arrow). 1 Reopen the neck and visualize the right CCA. 2 Apply the clip deeply to the right CCA just proximal to the bifurcation. 3 Clip-occlude the right CCA to complete the $3-\mathrm{VO}$ procedure. 4 Wait $15 \mathrm{~min}$, covering the exposed CCAs to protect from drying up using the fat tissue as a cap. 

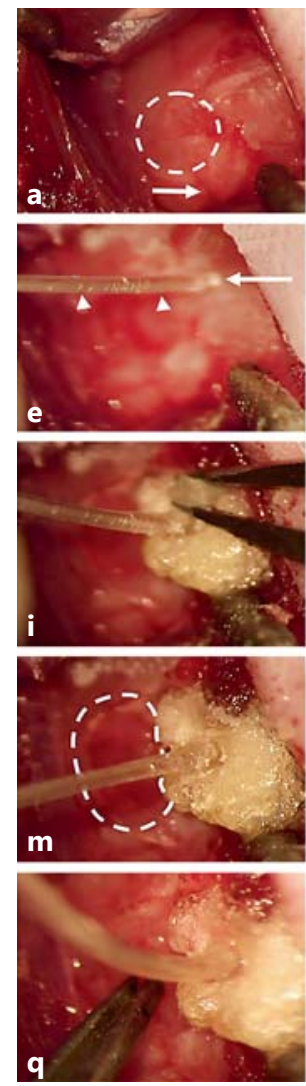

Fig. 2. Procedures of the rCBF monitoring. a Expose the surface of the temporal bone [dashed circle: the location of burr hole; arrow: the nerve (trigeminal) impression on the bone]. b Mill the temporal bone by gentle touches with the drill. c The left MCA (arrow) through the thinned temporal bone. $\mathbf{d}$ After the removal of the residual bone pieces with the microforceps (arrow: the MCA; asterisk: the location to set the laser probe on the temporal bone). e Put the tip (arrow) of the probe (triangles) at the location on the temporal bone. $f$ Dip the glue onto the 17-gauge needle (asterisk) first and transfer it to the fiber probe (arrow). The glue slowly goes down to the surface of the temporal bone by gravity. $\mathbf{g}$ The glue spreads over the temporal bone (dashed loop), including the burr hole. $\mathbf{h}$ Take a small piece of antibiotic powder (arrow) with the microforceps, which is used as an accelerator of the glue, and put

ischemia for $15 \mathrm{~min}$, remove the CCA clips to allow reperfusion. The duration of ischemia may be adjusted according to the animal or experimental purposes.

- After the removal of the neck clips, suture the incised skin in the head and neck and terminate general anesthesia to finish the operation. Note: avoid postischemic hypothermia by placing mice in an appropriate temperature-regulated place. Confirm the body temperature is in the normal range at least $15 \mathrm{~min}$ after ischemia [44].
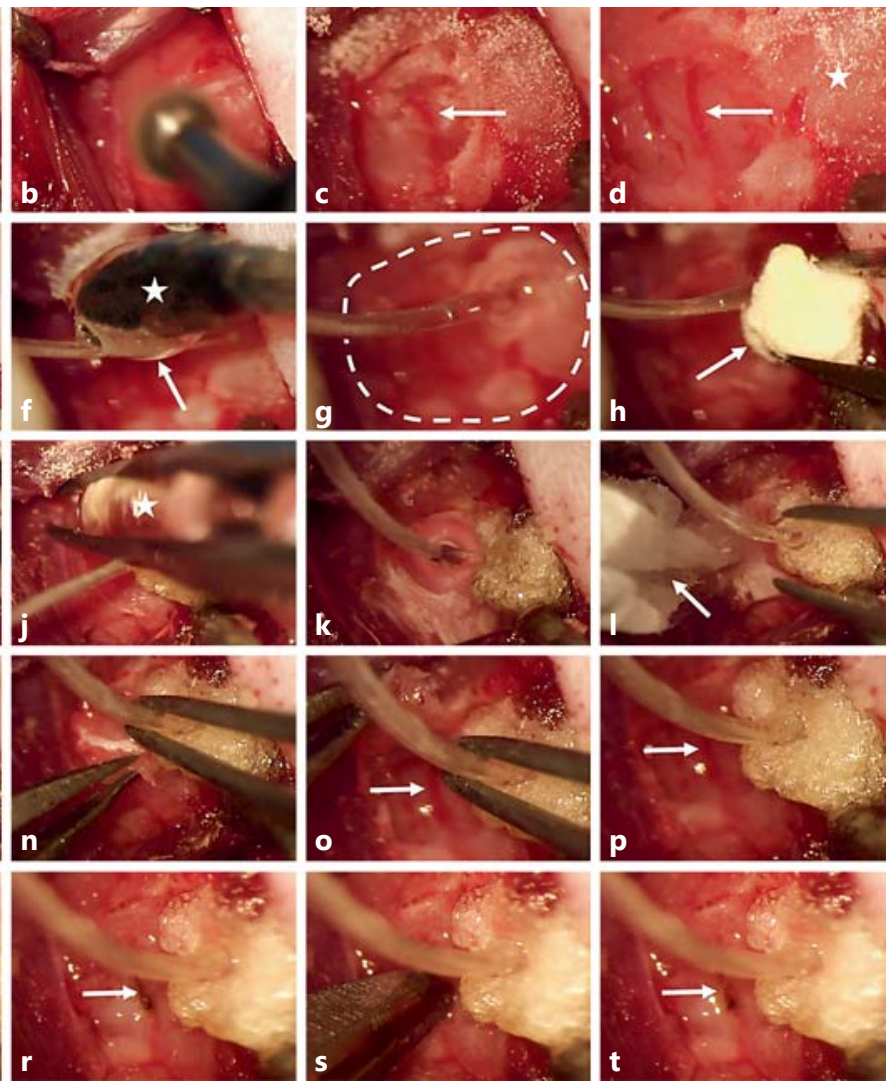

it on the glue. i Mix the powder with the glue to accelerate the solidification of the glue. $\mathbf{j}$ Fill the surgical field with saline using the space between the microforceps (asterisk). $\mathbf{k}$ Saline also accelerates the solidification of the glue. I Absorb saline in the surgical field with gauze (arrow). $\mathbf{m}$ Confirm the fixation of laser probe and the solidification of the glue over the burr hole (dashed loop). $\mathbf{n}$ Remove the excessive part of the glue formed into a thin sheet over the bone. o Removal of the glue sheet visualizes the MCA (arrow). p Total exposure of the burr hole and the MCA (arrow). q Occlude the left MCA using the bipolar coagulator. $\mathbf{r}$ Confirm the coagulation of the MCA (arrow). s Cut the MCA at the coagulated site to interrupt the blood flow permanently. $\mathbf{t}$ Confirm the edge and complete dissection of the MCA (arrow).

\section{Evaluation of Neurological Deficits}

The functional consequences caused by the focal ischemia were examined according to the scoring scale $[45,46]$. Balance in the body trunk while being lifted by the tail was graded in line with the following criteria: $0=$ no deficit (no twisting of the body), $1=$ mild deficit (asymmetric twisting tendency of the body), and $2=$ severe deficit (repeated asymmetric twisting of the body). Motor function of the extremities while being lifted by the tail was graded as follows: 0 = no deficit (symmetrical movement of the forelimbs), $1=$ mild deficit (intermittent asymmetrical flexion of the forelimbs), and $2=$ severe deficit (continuous asymmetrical flexion of the fore-
10

Eur Neurol 2014;71:4-18 DOI: $10.1159 / 000356048$
Yang/Nakajo/Iihara/Kataoka/ Nakagawara/Zhao/Yanamoto 
Fig. 3. a Mouse brain slices (1-mm thick) stained by TTC solution $24 \mathrm{~h}$ after the induction of $3-\mathrm{VO}$ ischemia. The infarcted lesion in the acute phase began to liquefy within 1 week $(1 \mathrm{~W})$, and was completely liquefied at 2 weeks $(2 \mathrm{~W})$. b The cortical infarction increased over time, but did not achieve a significant difference ( $\mathrm{p}=0.052 ; \mathrm{n}=10$ /group). $\mathbf{c}$ The infarct lesion volume was analyzed $24 \mathrm{~h}$ after 1-, 2-, and 3-VO. Cortical infarction developed in 14, 75 , and $100 \%$ of the cases after the induction of ischemia by 1-, 2-, and $3-\mathrm{VO}$, respectively ( $\mathrm{n}=7-8$ /group). The number indicates IVC in each method. $\mathrm{p}=$ permanent; $\mathrm{m}=$ modified temporary for 15 min (only the MCA occlusion is present).

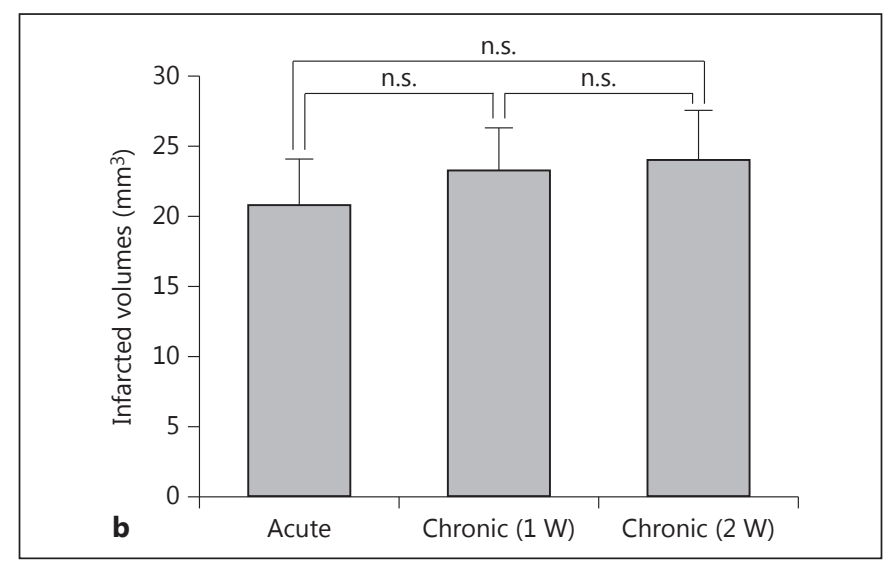

limbs). The neurological deficit score (from 0 to 4 ) comprises the sum of the grades of the balance in the body trunk and motor function of the extremities.

\section{Measurement of Infarct Lesion Volumes}

The infarct lesion volumes were analyzed at $24 \mathrm{~h}$ (acute phase study), or 1 or 2 weeks (chronic phase study) after ischemia ( $\mathrm{n}=$ 20 in each group). We also produced 1-, 2-, and 3-VO models to compare the variability in the induction rates and the depths of ischemia ( $\mathrm{n}=10$ in each group). The animals were deeply anesthetized and perfused intracardially with $20 \mathrm{ml}$ of ice-cold heparinized sodium PBS (10 mM, pH 7.5) at 50-60 mm Hg to wash blood components from the vessels in the brain. The brain was removed, cut coronally from the frontal tip into 1-mm thick slices, and stained by a $2 \%$ solution of $2,3,5-$ TTC [47]. Stained slices were fixed by immersion in $4 \%$ paraformaldehyde PBS. The absolute size $\left(\mathrm{mm}^{3}\right)$ of the cortical infarction (white area) and the total
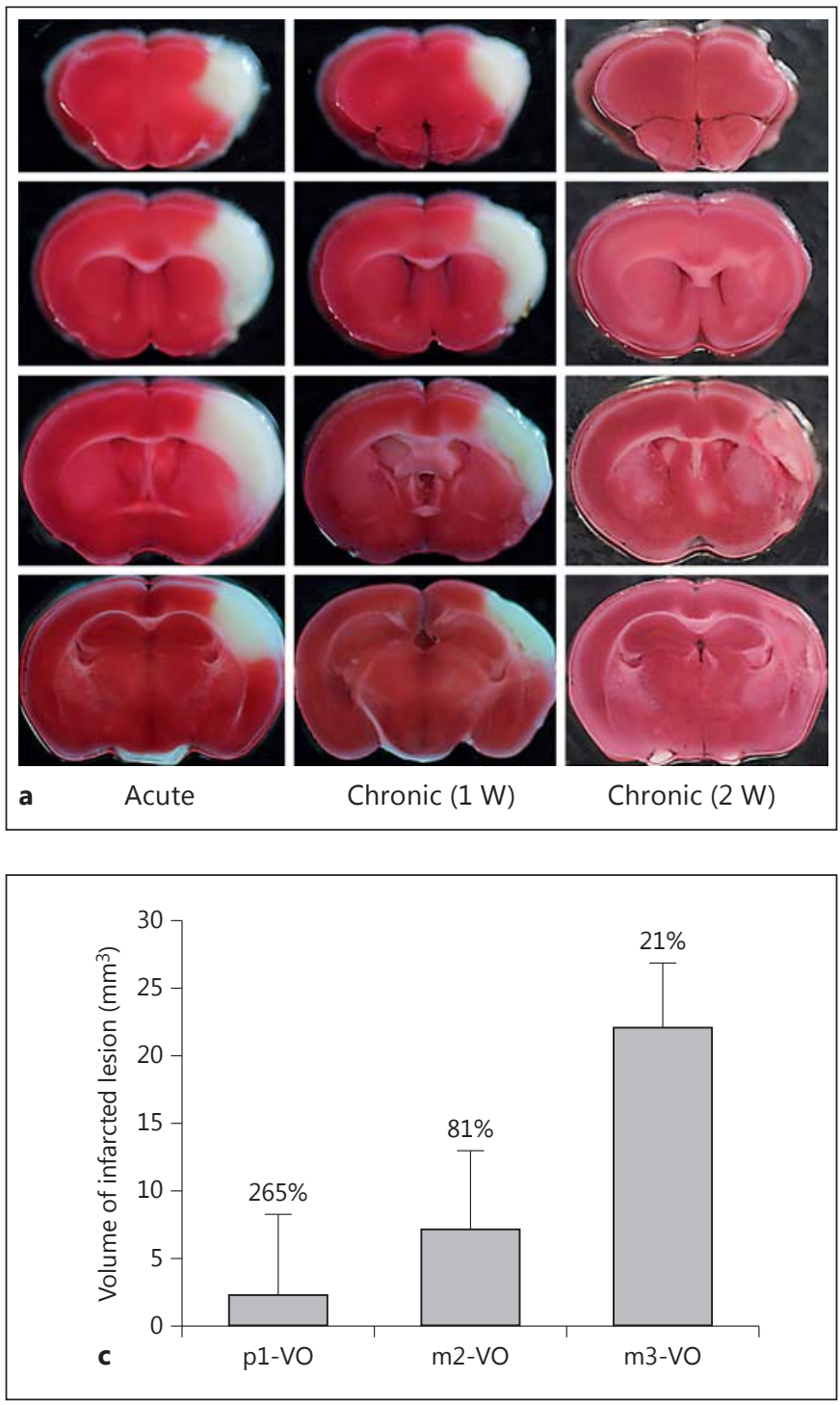

hemisphere were measured in all slices by tracing the borders with a computer-assisted image-analysis system (WinROOF).

In the acute phase, an edema index (the volume of the left hemisphere divided by the volume of the right hemisphere) was used to obtain the infarct index (the infarction volume divided by the edema index), eliminating the influence of brain edema. The infarct index represents the absolute infarct volume, excluding any enlargement due to cerebral edema. In the chronic phase, the infarct volume, calculated by subtracting the volume of the intact part of the left cortex from the volume of the right cortex, includes acute necrosis plus the volume that represents delayed cerebral atrophy [46].

\section{Determination of $r C B F$}

Alterations in $\mathrm{rCBF}$ were monitored using by laser-Doppler blood flowmetry at the peripheral area among the ischemic region. All of the whole procedures are shown in figure 2. Set the fiber probe at $1 \mathrm{~mm}$ caudal to the occluded/cut site of the MCA. Use the 


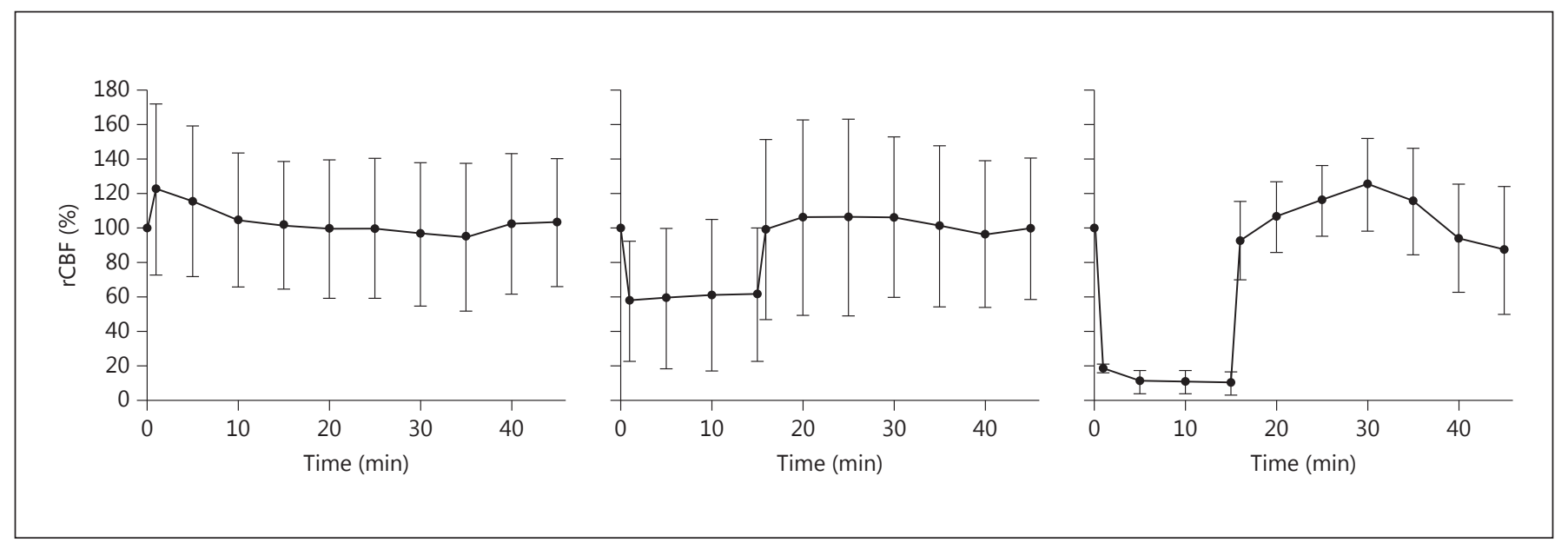

Fig. 4. The alteration in $\mathrm{rCBF}$ after permanent $1-\mathrm{VO}$ (left), 15-min 2-VO (center) or 15-min 3-VO (right) in comparison with the preischemic control. There was no significant reduction in $\mathrm{rCBF}$ after 1-VO; however, although not significant, a paradoxical increase occurred rapidly after the MCA occlusion, probably due to the vascular reserve system in the cortex that rescues the ischemic region by dilating collateral arteries. The $\mathrm{rCBF}$ value was significantly reduced after $3-\mathrm{VO}(\mathrm{n}=7-8$ /group).
laser-Doppler blood flowmetry before, during, and after 3-VO. It is necessary to avoid all visible small vessels when the probe is placed with the aid of a surgical microscope. Laser-Doppler recordings are expressed as percentages of the preischemic baseline. Note: when obtaining the rCBF value before the induction of ischemia as a control, confirm the removal of the clip at the left CCA that prevented bleeding during surgery in the left face. For placement of the laser probe, a wide exposure of the temporal bone is needed on the right side of the burr hole. Prior to glue fixation of the probe, needle retractors at each of the four corners is recommended to obtain a wide field of operation. A small amount of glue is enough to fix the laser probe onto the bone surface. Avoid getting glue on the retractors or surrounding muscles.

\section{Statistical Analysis}

All data are presented as the means \pm SD. Several general linear model procedures including multivariate repeated measures, one-way or two-way ANOVA can be applied to compare the variance within the different parameters. Neurological deficit scores were analyzed by the nonparametric Kruskal-Wallis analysis of ranks. Survival rates were analyzed by Kaplan-Meier survival analysis: log-rank test. $\mathrm{p}<0.05$ was considered to be statistically significant.

\section{Results}

Every animal survived at the time point $24 \mathrm{~h}$ after the induction of $15-\mathrm{min} 3-\mathrm{VO}$ in the series of 50 consecutive mice. There was no significant difference in body temperature, heart rate, and mean blood pressure over the observation period before, during, and after the induction of ischemia.

\section{Analyses of the Infarct Volume}

In each mouse, the development of cerebral infarction visualized by TTC staining after 3 -VO was limited to the left cortex in the MCA territory. The representative 1-mm thick brain slices stained with TTC solution are shown in figure 3a. The border of the TTC stain is well demarcated, enclosing a white-infarct area in contrast to red-stained normal brain.

The edema index in the acute phase was $1.12 \pm 0.03$. The infarct volumes were $20.8 \pm 3.2 \mathrm{~mm}^{3}$ (IVC: $15 \%$ ), $23.2 \pm 3.1 \mathrm{~mm}^{3}(13 \%)$, and $24.0 \pm 3.5 \mathrm{~mm}^{3}$ (15\%), $24 \mathrm{~h}$ (acute), 7 days (chronic $1 \mathrm{~W}$ ), or 14 days (chronic $2 \mathrm{~W}$ ) (mean $\pm \mathrm{SD}$ ) after ischemia, respectively (fig. $3 \mathrm{~b}$ ). The mean infarct lesion volumes developed $24 \mathrm{~h}$ after $1-\mathrm{VO}$, 15-min 2-VO, and 15-min 3-VO, with rCBF monitoring for $40 \mathrm{~min}$ after the induction of ischemia, are shown in figure $3 \mathrm{c}$.

\section{Measurement of $r \mathrm{CBF}$}

The rCBF values in the MCA territory in the cortex, peripheral to the ischemic core, are shown in figure 4 . The rCBF values demonstrated levels of ischemia after 1-VO (permanent without reperfusion), 2-VO, and 3-VO (with reperfusion). The reduction in $\mathrm{rCBF}$ induced by $3-\mathrm{VO}$ was the sole intervention that achieved the critical range of $\mathrm{rCBF}>10 \%$ but $<20 \%$, which is needed for the generation of a penumbral area.
Yang/Nakajo/Iihara/Kataoka/ Nakagawara/Zhao/Yanamoto 


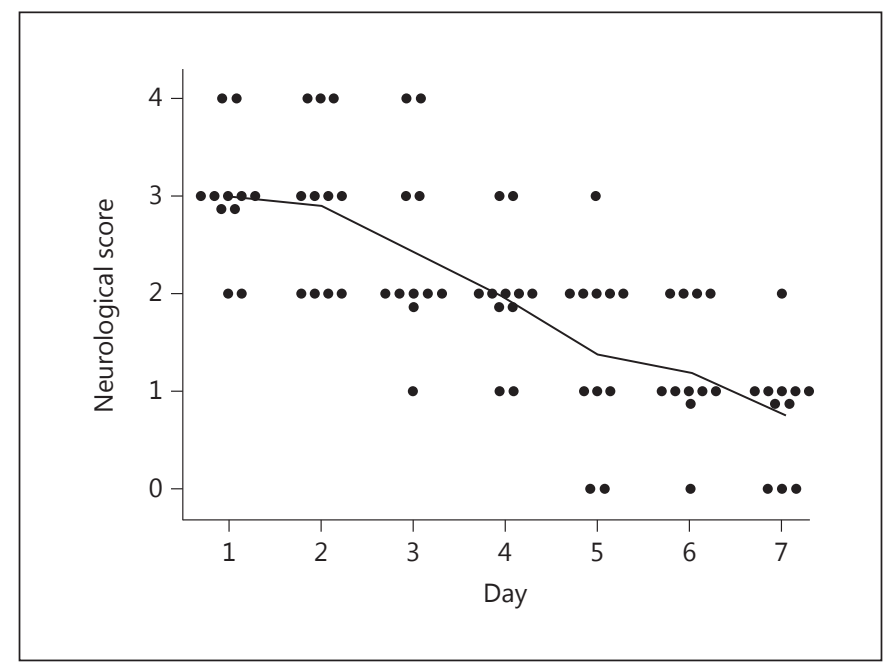

Fig. 5. Alterations in the neurological deficit scores. The score in the acute phase improved gradually into the chronic phase $(\mathrm{n}=$ $10)$.

Assessment of Neurological Function and Survival

The neurological deficit scores assessed $24 \mathrm{~h}$ and 2 , $3,4,5,6$, and 7 days after $3-\mathrm{VO}$ ischemia are shown in figure 5 . The score in the acute phase $(3.0 \pm 0.9) \mathrm{im}$ proved to a third of the initial level 7 days after ischemia. More animals survived in the group of 12- to 13-week-old mice compared to the 8- to 9-week-old mice, although the difference in the survival rates was not significant in the present size $(\mathrm{p}=0.08, \mathrm{n}=42$ in total; fig. 6).

\section{Discussion}

In this study, we attempted to generate a penumbral region ( $\mathrm{rCBF}>10 \%$ but $<20 \%$ of preischemic control values) by the 1 (single)-VO, 2 (tandem)-VO, or 3 (multiple)$\mathrm{VO}$ method in mice (fig. 1c), and demonstrated that single or tandem occlusion does not cause a significant reduction that is consistently below the upper threshold. Because of the cerebrovascular reserve system, simple occlusion of the MCA trunk did not generate infarcted lesions of consistent size in the cortex.

Regarding the relationship between the number of occluded arteries and the incidence of cerebral infarction in normotensive rats, permanent occlusion of the MCA orifice (1-VO, the arterial origin; $1-2 \mathrm{~mm}$ ) by a vascular

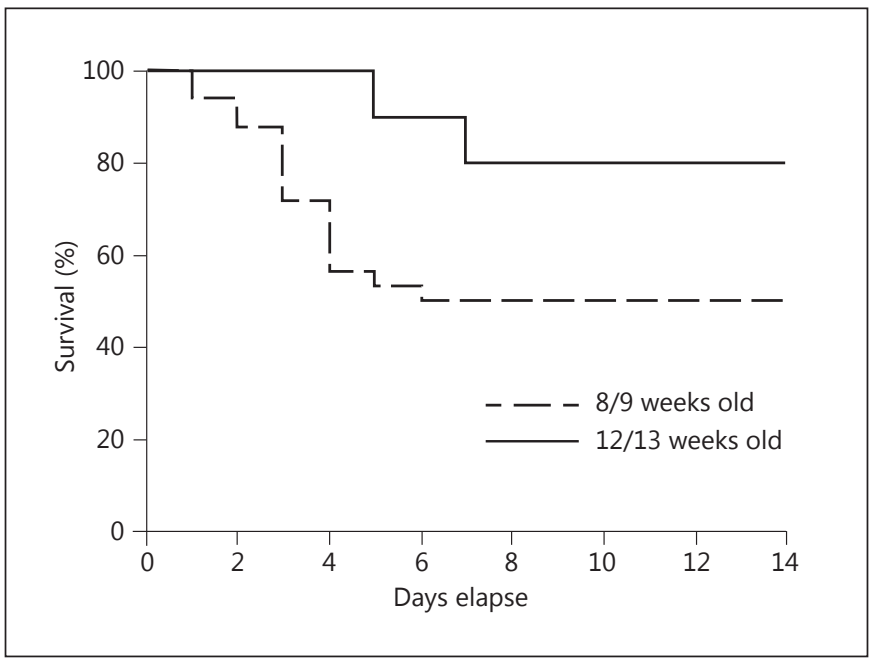

Fig. 6. Alterations in the survival rate after the induction of 15 -min 3 -VO ischemia. All animals survived after ischemia in the acute phase. The survival rate in the chronic phase decreased to $50 \%$ in the group of 8 - to 9 -week-old mice $(\mathrm{n}=32)$, but only to $80 \%$ in the 12- to 13-week-old animals $(\mathrm{n}=10)$.

clip, which does not stimulate the coagulation system in the blood or generate multiple embolisms, resulted in cerebral infarction in only $13 \%$ of cases [48]. The wellknown 1-VO method [49] targeting the proximal MCA (in the M1 segment), the location where the lenticulostriate perforating arteries of the basal ganglia originate, provides a reliable model for causing reproducible infarctions in the basal ganglia, but generates infarctions of varying size in the cortex [50].

Furuya et al. [51] reported a $1-\mathrm{VO}$ model using C57BL/6J mice (the strain used in this study and also the strain most widely used to generate transgenic animals) in which clip-occlusion of the MCA (1-VO) for $1-2 \mathrm{~h}$, at a location proximal to the olfactory branch, achieved rCBF that was $30 \%$ of preischemic control values on average, providing infarcted lesions with IVC values of 15$32 \%$, and mortality rates of $18-20 \%$ at $24 \mathrm{~h}$ (the anatomical distribution of the infarcted lesion was not described). The IVC value and the mortality rate were low to moderate in their 1-VO model, but the time needed for generation of consistently ischemic lesions was relatively long (the equivalent of about $12-24 \mathrm{~h}$ in humans).

Permanent occlusion of the proximal MCA and the ipsilateral internal carotid artery (permanent 2-VO, tandem) has also led to the development of an infarct of varying size in the cortex of normotensive rats, ranging from $38 \pm 50$ to $209 \pm 34 \mathrm{~mm}^{3}$ (IVC: $16-132 \%$ ) [50]. In other 
words, the 2-VO method involving the proximal portion of the MCA, a similar strategy to that utilized in the ITI method, produces substantial variability in IVC values. Because of the system of cerebrovascular reserve, it is difficult to induce a consistent reduction in $\mathrm{rCBF}$ below $20 \%$, in order to generate a penumbral area, using the $1-\mathrm{VO}$ or $2-\mathrm{VO}$ methods. In contrast, the 3 -VO technique has consistently generated a penumbral area, with an rCBF between 10 and 20\% (fig. 1c, 2 right).

Temporary 3-VO does not cause thrombus/embolus formation [29]. On the other hand, pharmaceutical or thrombin-induced MCA occlusion models [52] are designed to cause severe stagnation in the bloodstream that stimulates the intravascular coagulation system, resulting in thrombus/embolus formation and hemostasis-induced segmental occlusion. Such segmental occlusion tends to cause localized multivessel occlusion, which reduces vascular reserve and increases the probability of cerebral infarction. In the permanent 3-VO occlusion model with vascular clips, without the insertion of a foreign body that stimulates the coagulation system, the reduction in the rCBF was not permanent, but recovered to $>30 \%$ of the preischemic value within $4 \mathrm{~h}$ after the induction of ischemia [53]. It was thus demonstrated that permanent 3-VO without blood stagnation or coagulation in the vascular lumen is not accompanied by a persistent reduction in $\mathrm{rCBF}$, probably due to compensatory gradual dilatation of collaterals. Such a delayed activation of vascular reserve can not rescue the brain under ischemic penumbra without the induction of hypothermia [53] or other neuroprotective interventions, but it may prevent the expansion of the tissue damage.

In the ITI method, an adequate reduction in $\mathrm{rCBF}$ of below $20 \%$, which is needed for the induction of an infarcted lesion, was achieved in just $46 \%$ of cases in the primary thread trial, and another $10 \%$ achieved successful reduction with filament correction based on $\mathrm{rCBF}$ monitoring in Sprague-Dawley rats [28]. In order to exclude cases of incomplete vessel occlusion, and also to exclude cases of thread insertion-derived traumatic subarachnoid hemorrhage that increases IVC, bilateral monitoring of $\mathrm{rCBF}$ in each animal was essential and an exclusion of animals (34\%) with no infarction was necessary to obtain a low IVC in the ITI model [28]. When the ITI method was applied to C57BL/ 6 mice, $42 \%$ of cases had to be excluded because of spontaneous recovery in $\mathrm{rCBF}$ of above $30 \%$ during the thread-insertion period, which led to no or only faint development of an infarcted lesion [37]. Thus, the success rates in the ITI method in both rats and mice are similar.
In the ITI method, apart from the variability in volumes, infarcted lesions easily spread beyond the MCA territory, including to the thalamus, hypothalamus, hippocampus, substantia nigra, and retina, probably via thrombus/embolus formation on the surface of the inserted thread [36, 38, 54]. Moreover, it is known that a slight difference in thread characteristics (diameter, tensile strength, and extensibility) causes great variability in infarct lesion volumes and their reproducibility [35], and there has been criticism that the data obtained using the ITI model are still far from being standardized worldwide [51]. Numerous modifications of occlusive thread have been reported, including the recent proposal that the length of the thread coating should be adjusted to avoid occlusion of the ipsilateral posterior communicating artery and the subsequent expansion of the ischemic lesion into the posterior cerebral artery territory that results in development of massive cerebral infarction and acute death in C57BL/6 mice $[55,56]$.

In primates (baboons), proximal MCA clip occlusion (1-VO) for 6 h generated cerebral infarction limited to the basal ganglia in $60 \%$ (6/10 cases) of animals [57]. Proximal MCA balloon occlusion ( 1 or 2-VO) for $1 \mathrm{~h}$ produced a small infarction limited to the basal ganglia in $67 \%(4 / 6$ cases), and with a high mortality rate of $33 \%$ at $14 \mathrm{~h}$ after reperfusion in the rhesus macaque (Macaca mulatta) [58]. These data on primates demonstrate that the 1- or 2 -VO strategy is particularly limited in terms of generating infarcted lesions of consistent size. In contrast, using a modified 3-VO method (both anterior cerebral arteries and the MCA distal to the orbitofrontal branch) for $1 \mathrm{~h}$ produced moderate-sized infarcted lesions in the cortex $(25.8 \pm 2.1 \%$, IVC: $8.1 \%, n=5)$, with no mortality at $48 \mathrm{~h}$ in rhesus macaques [59]. Thus, the consequences of 1-, 2-, and 3-VO in both rodents and primates are similar.

The adequacy of the MCA model in the evaluation of neuroprotective intervention depends on the achievement of an appropriate reduction in the rCBF. Although 3 - VO was designed to produce an ischemic penumbra consistently for a specified period, an identical 3-VO pattern with the same onset seldom occurs in humans. Regarding the general relevance of the 3-VO method to clinical stroke, the anatomy of cerebral arteries comprising the anterior, middle, posterior, and communicating arteries, perforating arteries in the basal ganglia, and abundant anastomoses in the cortex are the same for rodents, primates, and humans. Therefore, the significance of the vascular reserve system in the cortex and the strategy needed to generate ischemic penumbra do not differ between primates and rodents. Based on this common ana- 
tomical background, the occlusion of both CCAs is not an emulation of human stroke, but instead a substitute of the state with appropriately reduced vascular reserve [15].

The logic and rationale for the 3-VO occlusion technique in rodents and primates is as follows. Permanent loss of MCA perfusion is not by itself sufficient to produce reliable infarcts due to the capacity of the collateral vasculature to maintain adequate blood flow to its territory. Since the preponderance of the literature indicates that even severe ischemia, although perhaps producing some selective loss of vulnerable neurons, does not lead to consistent cortical infarction, it would therefore appear that reducing collateral perfusion (for only $15 \mathrm{~min}$ in mice, or $1 \mathrm{~h}$ in primates) results in a state of more severe vascular insufficiency than would have persisted if only the MCA had been occluded. Perhaps this reflects a transition to a state characterized by constrictive vascular responses, i.e. an inverse hemodynamic response to spreading depolarization or intermediate peri-infarct (ischemic) depolarization in the peri-infarct region [13], referred to as monophasic hypoperfusion [60]. Theoretically, neurons in the ischemic penumbra can survive for a prolonged period if sufficient dilatation of the collaterals occurs (as observed in the stage 2). Transient depression of electrical activity on EEG caused by spreading depolarization and lasting for a few minutes in tissue under nonischemic normal conditions is accompanied by vasodilatation of collaterals and hyperemia $[13,61]$. However, such compensatory, dilative vascular responses have not been observed in the peri-infarct area in positron emission tomography studies of patients with acute ischemic stroke (unpubl. observation). In accord with this finding, monophasic hypoperfusion (caused by reactive, prolonged vasoconstriction) can be observed at the peri-infarct region, where a cluster of intermediate peri-infarct or ischemic depolarizations were found to cause persistent depression of electrical activity (persistent electrical silence) $[13,60]$. It is likely that persistent electrical silence (persistent depression of neuronal activity) with preserved energy metabolism is integral to the definition of ischemic penumbra.

Currently, there is no evidence to suggest that primate ischemic models are superior to rodent models in the assessment of ischemic damage in the brain. We believe that it is not rodent models or the body sizes, but researcher manipulation of rodent models that has become unreliable. Without the consideration of the cerebrovascular reserve system, an intrinsic mechanism to prevent focal ischemia, especially to protect the cortex after $1-$ or $2-\mathrm{VO}$, the unfavorable situation in rodent models, i.e. failing to

Reproducible Ischemic Penumbra in the Mouse Brain conduct appropriate evaluations of ischemic injuries and disclose excluded animals, may also occur in primates.

Because a pure cortical infarct in the MCA territory is not considered lethal and the mortality rate was reduced in slightly (4-weeks) older mice, it is possible that drinking and eating disturbances in the acute phase after surgery affected survivability in mice. Whether appropriate nutritional management in the acute phase may reduce the mortality rate, as was observed in this study, is a matter requiring further investigation.

Regarding the choice of anesthetics, it has been reported that significant respiratory depression was not observed with isoflurane, sevoflurane, or halothane in mice [62]. Although there is a transient increase in plasma lactate levels after ischemia $[63,64]$, isoflurane has been used as an alternative to halothane in mice [36], where halothane has not been readily available.

We utilized the TTC method that visualizes surviving neurons and proliferation of reactive astrocytes (gliosis) in the acute and chronic phase, rather than utilizing the cresyl violet method that stains only surviving neurons. It was found that the infarct lesion rates in the total hemisphere were almost identical for both methods, but the brain tissue including degenerating and dead tissues shrank to $66 \%$, on average, of the original volume after the dehydration procedure that forms part of the cresyl violet method, making it unsuitable for a chronological comparison [65]. In addition, the volume of gliosis in the chronic phase that can be visualized with glial fibrillary acidic protein was negligible in the analysis of infarcted volumes in the cortex. This was because measurable gliosis was found only in the corpus callosum below the cortical lesion, rather than in the border zone of focal ischemia in the cortex [65].

In the manipulation of animals, it is important to recognize that the rate of passage of biological time is correlated inversely with [body weight] ${ }^{2}$, as represented by longevity and heart/respiration rate among animal species [66]. The biological time of $15-30 \mathrm{~min}$ in mice is regarded as $30 \mathrm{~min}$ to $1 \mathrm{~h}$ in rats [67], and $3-6 \mathrm{~h}$ in humans [68]. Seven days after ischemia in mice can be translated into 3 months in humans, a sufficient time for a mild-tomoderate neurological deficit to improve.

The new 3-VO model consistently induced temporary focal ischemia with a critical, but treatable, reduction in rCBF of $10-20 \%$ in the cortex, within the ischemic penumbra, which achieves a shorter, less invasive duration of surgery compared to other mouse models in the literature where the duration of ischemia was 30 (40) $\mathrm{min}$ [69], 60 $\min [39,51], 90 \mathrm{~min}[40,41,70]$, or $120 \mathrm{~min}$ [51]. Com- 
pletion of surgery takes $10 \mathrm{~min}$ (as shown in the online suppl. video) excluding the time for $15 \mathrm{~min}$ of ischemia.

To detect a 30\% improvement in the mean infarct lesion volume, the previous $15-\mathrm{min} 3-\mathrm{VO}$ model required 42 animals in both placebo and treatment groups, with $80 \%$ power (1- $\beta$ ) in a t test based on normal distribution [29], whereas the present model only requires 10 mice [46, 71]. Concerning the mortality rate in this model, the 4-week-older condition, or the age-dependent 3-gram (11-13\%) gain in body weight, reduced the mortality rate in the chronic phase. Further investigations are needed to identify standard infarct lesion volumes for different ages, different nutritional statuses, and different species and genders.

\section{Conclusion}

We have demonstrated a new 3-VO model with a brief operation time, a low IVC value, and a low mortality rate after the induction of ischemia. This 3 -VO model can produce an ischemic penumbra of consistent size. Our established methodology is expected to produce reliable preclinical evidence in the assessment of interventions that treat the ischemic penumbra, aiming to protect the brain from ischemic stroke.

\section{Acknowledgements}

We thank the valuable assistance of Takuma Irie at Japan Focus Co. Ltd. as well as Nozomi Momosaki and Eri Shiozuka from the Laboratory of Neurology and Neurosurgery. This work was supported by the Japan Cardiovascular Research Foundation and Japan-China Sasakawa Medical Fellowship.

\section{Disclosure Statement}

The authors have no conflicts of interest to declare.

\section{References}

1 Liu S, Zhen G, Meloni BP, Campbell K, Winn HR: Rodent stroke model guidelines for preclinical stroke trials (1st ed). J Exp Stroke Transl Med 2009;2:2-27.

-2 Macleod MR, Fisher M, O'Collins V, Sena ES, Dirnagl U, Bath PM, Buchan A, van der Worp HB, Traystman R, Minematsu K, Donnan GA, Howells DW: Good laboratory practice: preventing introduction of bias at the bench. Stroke 2009;40:e50-e52.

- 3 O'Collins VE, Macleod MR, Donnan GA Horky LL, van der Worp BH, Howells DW: 1,026 experimental treatments in acute stroke. Ann Neurol 2006;59:467-477.

-4 Fisher M, Albers GW, Donnan GA, Furlan AJ, Grotta JC, Kidwell CS, Sacco RL, Wechsler LR: Enhancing the development and approval of acute stroke therapies: Stroke Therapy Academic Industry roundtable. Stroke 2005; 36:1808-1813.

5 Fisher M, Hanley DF, Howard G, Jauch EC, Warach S: Recommendations from the STAIR $\mathrm{V}$ meeting on acute stroke trials, technology and outcomes. Stroke 2007;38:245-248.

6 Savitz SI: A critical appraisal of the NXY-059 neuroprotection studies for acute stroke: a need for more rigorous testing of neuroprotective agents in animal models of stroke. Exp Neurol 2007;205:20-25.

-7 Astrup J, Siesjo BK, Symon L: Thresholds in cerebral ischemia - the ischemic penumbra. Stroke 1981;12:723-725.
8 Astrup J, Symon L, Branston NM, Lassen NA: Cortical evoked potential and extracellular $\mathrm{K}+$ and $\mathrm{H}+$ at critical levels of brain ischemia. Stroke 1977;8:51-57.

19 Heiss WD: The ischemic penumbra: correlates in imaging and implications for treatment of ischemic stroke. The Johann Jacob Wepfer Award 2011. Cerebrovasc Dis 2011; 32:307-320.

10 Back T, Kohno K, Hossmann KA: Cortical negative DC deflections following middle cerebral artery occlusion and $\mathrm{KCl}$-induced spreading depression: effect on blood flow, tissue oxygenation, and electroencephalogram. J Cereb Blood Flow Metab 1994;14:12-19.

11 Back T: Pathophysiology of the ischemic penumbra - revision of a concept. Cell Mol Neurobiol 1998;18:621-638.

12 Dohmen C, Sakowitz OW, Fabricius M, Bosche B, Reithmeier T, Ernestus RI, Brinker G, Dreier JP, Woitzik J, Strong AJ, Graf R: Spreading depolarizations occur in human ischemic stroke with high incidence. Ann Neurol 2008;63:720-728.

13 Dreier JP: The role of spreading depression, spreading depolarization and spreading ischemia in neurological disease. Nat Med 2011; 17:439-447.

14 Patil SB, Khan MK: Germinated brown rice as a value added rice product: a review. J Food Sci Technol 2011;48:661-667.
15 Derdeyn CP, Powers WJ, Grubb RL Jr: Hemodynamic effects of middle cerebral artery stenosis and occlusion. AJNR Am J Neuroradiol 1998;19:1463-1469.

16 Hossmann KA: Viability thresholds and the penumbra of focal ischemia. Ann Neurol 1994:36:557-565

17 Lassen NA, Fieschi C, Lenzi GL: Ischemic penumbra and neuronal death: comments on the therapeutic window in acute stroke with particular reference to thrombolytic therapy. Cerebrovasc Dis 1991;1:32-35.

18 Powers WJ, Grubb RL Jr, Darriet D, Raichle ME: Cerebral blood flow and cerebral metabolic rate of oxygen requirements for cerebral function and viability in humans. J Cereb Blood Flow Metab 1985;5:600-608.

$\checkmark 19$ Memezawa H, Minamisawa H, Smith M-L, Siesjo BK: Ischemic penumbra in a model of reversible middle cerebral artery occlusion in the rat. Exp Brain Res 1992;89:67-78.

-20 Takeda Y, Zhao L, Jacewicz M, Pulsinelli WA Nowak TS Jr: Metabolic and perfusion responses to recurrent peri-infarct depolarization during focal ischemia in the spontaneously hypertensive rat: dominant contribution of sporadic CBF decrements to infarct expansion. J Cereb Blood Flow Metab 2011; 31:1863-1873.

21 Jacewicz M, Tanabe J, Pulsinelli WA: The $\mathrm{CBF}$ threshold and dynamics for focal cerebral infarction in spontaneously hypertensive rats. J Cereb Blood Flow Metab 1992;12:359_ 370
16
Eur Neurol 2014;71:4-18 DOI: $10.1159 / 000356048$
Yang/Nakajo/Iihara/Kataoka/ Nakagawara/Zhao/Yanamoto 
22 Belayev L, Zhao W, Busto R, Ginsberg MD: Transient middle cerebral artery occlusion by intraluminal suture: I. Three-dimensional autoradiographic image-analysis of local cerebral glucose metabolism-blood flow interrelationships during ischemia and early recirculation. J Cereb Blood Flow Metab 1997;17: $1266-1280$

23 Ginsberg MD: Adventures in the pathophysiology of brain ischemia: penumbra, gene expression, neuroprotection: the 2002 Thomas Willis Lecture. Stroke 2003;34:214-223.

24 Koizumi J, Yoshida Y, Nakazawa T, Ooneda G: Experimental studies of ischemic brain edema: a new experimental studies of ischemic brain edema: 1. A new experimental model of cerebral embolism in rats in which recirculation can be introduced in the ischemic area. Jpn J Stroke 1986;8:1-8.

25 Longa EZ, Weinstein PR, Carlson S, Cummins R: Reversible middle cerebral artery occlusion without craniectomy in rats. Stroke 1989;20:84-91.

-26 Bonventre JV, Huang Z, Taheri MR, O'Leary E, Li E, Moskowitz MA, Sapirstein A: Reduced fertility and postischaemic brain injury in mice deficient in cytosolic phospholipase A2. Nature 1997;390:622-625.

27 Yang G, Chan PH, Chen J, Carlson E, Chen SF, Weinstein P, Epstein CJ, Kamii H: Human copper-zinc superoxide dismutase transgenic mice are highly resistant to reperfusion injury after focal cerebral ischemia. Stroke 1994;25: 165-170.

-28 Schmid-Elsaesser R, Zausinger S, Hungerhuber E, Baethmann A, Reulen HJ: A critical reevaluation of the intraluminal thread model of focal cerebral ischemia: evidence of inadvertent premature reperfusion and subarachnoid hemorrhage in rats by laser-Doppler flowmetry. Stroke 1998;29:2162-2170.

29 Yanamoto H, Nagata I, Niitsu Y, Xue JH, Zhang Z, Kikuchi H: Evaluation of MCAO stroke models in normotensive rats: standardized neocortical infarction by the $3 \mathrm{VO}$ technique. Exp Neurol 2003;182:261-274.

- 30 Chen ST, Hsu CY, Hogan EL, Maricq H, Balentine JD: A model of focal ischemic stroke in the rat: reproducible extensive cortical infarction. Stroke 1986;17:738-743.

- 31 Korematsu K, Goto S, Nagahiro S, Ushio Y: Changes of immunoreactivity for synaptophysin ('protein p38') following a transient cerebral ischemia in the rat striatum. Brain Res 1993;616:320-324.

-32 Katchanov J, Waeber C, Gertz K, Gietz A, Winter B, Bruck W, Dirnagl U, Veh RW, Endres M: Selective neuronal vulnerability following mild focal brain ischemia in the mouse. Brain Pathol 2003;13:452-464.

- 33 Matsuo Y, Mihara Si, Ninomiya M, Fujimoto $\mathrm{M}$ : Protective effect of endothelin type A receptor antagonist on brain edema and injury after transient middle cerebral artery occlusion in rats. Stroke 2001;32:21432148.
34 Müller TB, Haraldseth O, Unsgard G: Characterization of the microcirculation during ischemia and reperfusion in the penumbra of a rat model of temporary middle cerebral artery occlusion: a laser Doppler flowmetry study. Int J Microcirc Clin Exp 1994;14:289295.

35 Kuge Y, Minematsu K, Yamaguchi T, Miyake Y: Nylon monofilament for intraluminal middle cerebral artery occlusion in rats. Stroke 1995;26:1655-1657.

-36 Steele EC Jr, Guo Q, Namura S: Filamentous middle cerebral artery occlusion causes ischemic damage to the retina in mice. Stroke 2008;39:2099-2104.

37 Chen Y, Ito A, Takai K, Saito N: Blocking pterygopalatine arterial blood flow decreases infarct volume variability in a mouse model of intraluminal suture middle cerebral artery occlusion. J Neurosci Methods 2008;174:18-24.

38 Kitagawa K, Matsumoto M, Yang G, Mabuchi T, Yagita Y, Hori M, Yanagihara T: Cerebral ischemia after bilateral carotid artery occlusion and intraluminal suture occlusion in mice: evaluation of the patency of the posterior communicating artery. J Cereb Blood Flow Metab 1998;18:570-579.

39 Teramoto S, Miyamoto N, Yatomi K, Tanaka Y, Oishi H, Arai H, Hattori N, Urabe T: Exendin-4, a glucagon-like peptide-1 receptor agonist, provides neuroprotection in mice transient focal cerebral ischemia. J Cereb Blood Flow Metab 2011;31:1696-1705.

-40 Shichita T, Hasegawa E, Kimura A, Morita R, Sakaguchi R, Takada I, Sekiya T, Ooboshi H, Kitazono T, Yanagawa T, Ishii T, Takahashi H, Mori S, Nishibori M, Kuroda K, Akira S, Miyake K, Yoshimura A: Peroxiredoxin family proteins are key initiators of post-ischemic inflammation in the brain. Nat Med 2012;18: 911-917.

41 Shichita T, Sugiyama Y, Ooboshi H, Sugimori H, Nakagawa R, Takada I, Iwaki T, Okada Y, Iida M, Cua DJ, Iwakura Y, Yoshimura A: Pivotal role of cerebral interleukin-17-producing gammadeltaT cells in the delayed phase of ischemic brain injury. Nat Med 2009; 15:946-950.

42 Vesterinen HM, Egan K, Deister A, Schlattmann P, Macleod MR, Dirnagl U: Systematic survey of the design, statistical analysis, and reporting of studies published in the 2008 volume of the Journal of Cerebral Blood Flow and Metabolism. J Cereb Blood Flow Metab 2011;31:1064-1072.

43 Sakatani K, Ohtaki M, Morimoto S, Hashi K: Isotonic mannitol and the prevention of local heat generation and tissue adherence to bipolar diathermy forceps tips during electrical coagulation. Technical note. J Neurosurg 1995;82:669-671.

44 Yanamoto H, Hong S-C, Soleau S, Kassell NF, Lee KS: Mild postischemic hypothermia limits cerebral injury following transient focal ischemia in rat neocortex. Brain Res 1996;718: 207-211.
45 Finklestein SP, Fanning PJ, Caday CG, Powell PP, Foster J, Clifford EM, Klagsbrun M: Increased levels of basic fibroblast growth factor (bFGF) following focal brain injury. Restor Neurol Neurosci 1990;1:387-394.

46 Yamamoto H, Kokame K, Okuda T, Nakajo Y, Yanamoto H, Miyata T: NDRG4-deficient mice exhibit spatial learning deficits and vulnerabilities to cerebral ischemia. J Biol Chem 2011;286:26158-26165.

47 Bederson JB, Pitts LH, Germano SM, Nishimura MC, Davis RL, Bartkowski HM: Evaluation of 2,3,5-triphenyltetrazolium chloride as a stain for detection and quantification of experimental cerebral infarction in rats. Stroke 1986;17:1304-1308.

48 Bederson JB, Pitts LH, Tsuji M, Nishimura MC, Davis RL, Bartkowski H: Rat middle cerebral artery occlusion: evaluation of the model and development of a neurologic examination. Stroke 1986;17:472-476.

49 Tamura A, Graham DI, McCulloch J, Teasdale GM: Focal cerebral ischaemia in the rat: 1. Description of technique and early neuropathological consequences following middle cerebral artery occlusion. J Cereb Blood Flow Metab 1981;1:53-60.

50 Brint S, Jacewicz M, Kiessling M, Tanabe J, Pulsinelli W: Focal brain ischemia in the rat: methods for reproducible neocortical infarction using tandem occlusion of the distal middle cerebral and ipsilateral common carotid arteries. J Cereb Blood Flow Metab 1988;8: 474-485.

51 Furuya K, Kawahara N, Kawai K, Toyoda T, Maeda K, Kirino T: Proximal occlusion of the middle cerebral artery in C57Black6 mice: relationship of patency of the posterior communicating artery, infarct evolution, and animal survival. J Neurosurg 2004;100:97-105.

52 Mergenthaler P, Meisel A: Do stroke models model stroke? Dis Model Mech 2012;5:718725 .

53 Yanamoto H, Nagata I, Niitsu Y, Zhang Z, Xue JH, Sakai N, Kikuchi H: Prolonged mild hypothermia therapy protects the brain against permanent focal ischemia. Stroke 2001;32:232-239.

54 Kanemitsu H, Nakagomi T, Tamura A, Tsuchiya T, Kono G, Sano K: Differences in the extent of primary ischemic damage between middle cerebral artery coagulation and intraluminal occlusion models. J Cereb Blood Flow Metab 2002;22:1196-1204.

55 Akamatsu Y, Shimizu H, Saito A, Fujimura $\mathrm{M}$, Tominaga T: Consistent focal cerebral ischemia without posterior cerebral artery occlusion and its real-time monitoring in an intraluminal suture model in mice. J Neurosurg 2012;116:657-664.

56 Yuan F, Tang Y, Lin X, Xi Y, Guan Y, Xiao T, Chen J, Zhang Z, Yang GY, Wang Y: Optimizing suture middle cerebral artery occlusion model in C57BL/6 mice circumvents posterior communicating artery dysplasia. J Neurotrauma 2012;29:1499-1505. 
57 Young AR, Touzani O, Derlon JM, Sette G, MacKenzie ET, Baron JC: Early reperfusion in the anesthetized baboon reduces brain damage following middle cerebral artery occlusion: a quantitative analysis of infarction volume. Stroke 1997;28:632-637.

58 Zhang J, Chen YM, Zhang YT: Blood-oxygenation-level-dependent-(BOLD-) based R2' MRI study in monkey model of reversible middle cerebral artery occlusion. J Biomed Biotechnol 2011;2011:318346.

59 West GA, Golshani KJ, Doyle KP, Lessov NS, Hobbs TR, Kohama SG, Pike MM, Kroenke CD, Grafe MR, Spector MD, Tobar ET, Simon RP, Stenzel-Poore MP: A new model of cortical stroke in the rhesus macaque. J Cereb Blood Flow Metab 2009;29:1175-1186.

-60 Strong AJ, Anderson PJ, Watts HR, Virley DJ, Lloyd A, Irving EA, Nagafuji T, Ninomiya M, Nakamura H, Dunn AK, Graf R: Peri-infarct depolarizations lead to loss of perfusion in ischaemic gyrencephalic cerebral cortex. Brain 2007;130:995-1008.

-61 Lasjaunias PL, Landrieu P, Rodesch G, Alvarez H, Ozanne A, Holmin S, Zhao WY, Geibprasert S, Ducreux D, Krings T: Cerebral proliferative angiopathy: clinical and angiographic description of an entity different from cerebral AVMs. Stroke 2008;39:878-885.
62 Schwarzkopf TM, Horn T, Lang D, Klein J: Blood gases and energy metabolites in mouse blood before and after cerebral ischemia: the effects of anesthetics. Exp Biol Med (Maywood) 2013;238:84-89.

63 Zapp M, Kofke WA, Davis DW: Comparison of the effects of volatile anesthetics in varying concentrations on brain energy metabolism with brain ischemia in rats. Neurochem Res 1992;17:301-305.

64 Horn T, Klein J: Neuroprotective effects of lactate in brain ischemia: dependence on anesthetic drugs. Neurochem Int 2013;62:251257.

65 Yanamoto H, Nagata I, Nakahara I, Tohnai N, Zhang Z, Kikuchi H: Combination of intraischemic and postischemic hypothermia provides potent and persistent neuroprotection against temporary focal ischemia in rats. Stroke 1999;30:2720-2726.

66 Calder WA 3rd: Body size, mortality, and longevity. J Theor Biol 1983;102:135-144.
67 Yanamoto H, Xue JH, Miyamoto S, Nagata I, Nakano Y, Murao K, Kikuchi H: Spreading depression induces long-lasting brain protection against infarcted lesion development via BDNF gene-dependent mechanism. Brain Res 2004;1019:178-188.

68 Yanamoto H, Kataoka H, Nakajo Y, Iihara K: The role of the host defense system in the development of cerebral vasospasm: analogies between atherosclerosis and subarachnoid hemorrhage. Eur Neurol 2012;68:329-343.

69 Barber PA, Hoyte L, Colbourne F, Buchan AM: Temperature-regulated model of focal ischemia in the mouse: a study with histopathological and behavioral outcomes. Stroke 2004;35:1720-1725.

70 Kilic E, Kilic U, Matter CM, Luscher TF, Bassetti CL, Hermann DM: Aggravation of focal cerebral ischemia by tissue plasminogen activator is reversed by 3-hydroxy-3-methylglutaryl coenzyme A reductase inhibitor but does not depend on endothelial NO synthase. Stroke 2005;36:332-336.

-71 Yang D, Nakajo Y, Iihara K, Kataoka H, Yanamoto H: Alogliptin, a dipeptidylpeptidase-4 inhibitor, for patients with diabetes mellitus type 2 , induces tolerance to focal cerebral ischemia in non-diabetic, normal mice. Brain Res 2013;1517:104-113. 